\title{
Изделия из керамики на основе оксида алюминия, нитрида алюминия и оксида бериллия от АО «ТЕСТПРИБОР"
}

\author{
А. Щербина ${ }^{1}$, Л. Федорович ${ }^{2}$
}

УДК 666.3-135 | ВАК 05.27.06

\begin{abstract}
Миниатюризация, создание высокоинтегрированных сборок и модулей при непрерывном повышении производительности электроники приводит к проблеме эффективного отвода тепла от электронных компонентов. Одним из путей ее решения в силовой электронике и микроэлектронике является применение в качестве подложек материалов с высокой теплопроводностью. В АО «ТЕСТПРИБОР" освоенЫ технологии изготовления однослойных и многослойных печатных плат и подложек из керамики на основе оксида алюминия, нитрида алюминия и оксида бериллия, которые обеспечивают высокую надежность различных изделий, в частности мощных РЧ- и СВЧ-передатчиков, силовых транзисторов и преобразователей, в условиях больших токов и высоких температур.
\end{abstract}

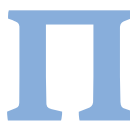

о мере повышения уровня мощности, эффективности, надежности и прочности электронных изделий ужесточаются требования к керамическим материалам, которыехарактеризуются рядом параметров, в частности максимальной рабочей температурой (МРТ), коэффициентом теплового расширения (КТР), электрической изоляцией (удельным сопротивлением), теплопроводностью и относительной диэлектрической проницаемостью. Для керамических материалов отработаны технологии нанесения тонких или толстых пленок, которые, помимо создания металлизации, позволяют реализовать пленочные компоненты, такие как резисторы, конденсаторы, катушки индуктивности

Освоенные в АО «ТЕСТПРИБОР» изделия из керамических материалов на основе $\mathrm{Al}_{2} \mathrm{O}_{3}$ (чистота 92, 96 и 99\%), AIN

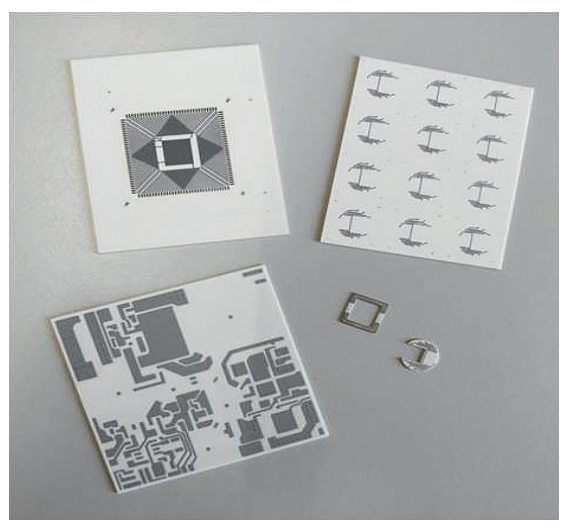

Рис. 1. Образцы керамических подложек с металлизацией

АО «ТЕСТПРИБОР», начальник отдела развития и технической поддержки.

АО "ТЕСТПРИБОР", инженер-технолог гальванического производства. и ВеО отличаются высокой теплопроводностью, низким коэффициентом теплового расширения, низкими диэлектрическими потерями и высокой механической прочностью (табл. 1 и 2). Компания изготавливает и поставляет спеченные керамические пластины толщиной от 0,127 до 2 мм различного состава.

Металлизация подложек и изделий из керамики осуществляется по толстопленочной технологии путем нанесения и вжигания паст, содержащих молибден и вольфрам, толщиной от 25 до 50 мкм (рис. 1). Возможно нанесение металлизации медью толщиной до 300 мкм для применения в силовых модулях на основе IGBT.

В процессе изготовления изделий выполняется механическая обработка керамики (резка, скрайбирование, прошивка отверстий) (рис. 2).

Металлизация (печать) наносится как на индивидуальные, так и на групповые заготовки, при этом расстояние между проводниками составляет не менее 50 мкм (рис. 3).

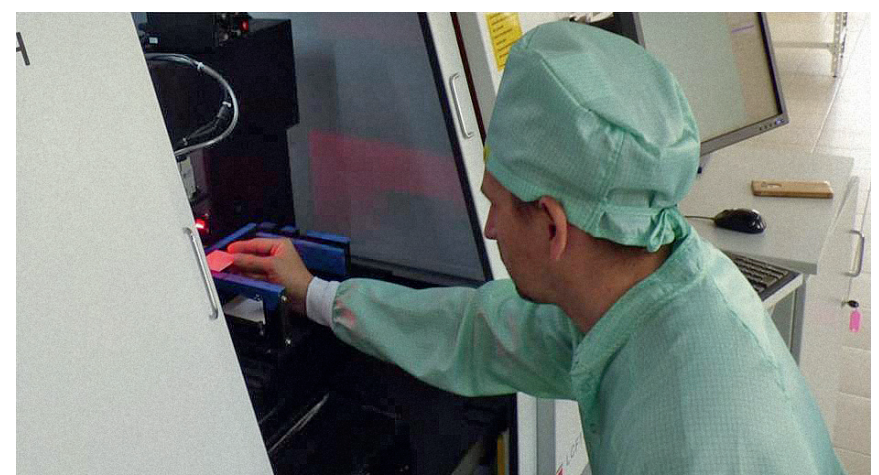

Рис. 2. Механическая обработка керамики 
Таблица 1. Характеристики керамических материалов для силовой электроники

\begin{tabular}{|c|c|c|c|c|}
\hline Материал (чистота) & $\begin{array}{c}\text { Оксид алюми- } \\
\text { ния }(99,5 \%)\end{array}$ & $\begin{array}{r}\text { Оксид алюми- } \\
\text { ния (96\%) }\end{array}$ & $\begin{array}{r}\text { Оксид берил- } \\
\text { лия (99,5\%) }\end{array}$ & $\begin{array}{r}\text { Нитрид } \\
\text { алюминия }\end{array}$ \\
\hline Химическая формула & $\mathrm{Al}_{2} \mathrm{O}_{3}$ & $\mathrm{Al}_{2} \mathrm{O}_{3}$ & $\mathrm{BeO}$ & AlN \\
\hline Температура плавления, ${ }^{\circ} \mathrm{C}$ & 2072 & 2072 & $2514-2626$ & $2397-2507$ \\
\hline Максимальная рабочая температура, ${ }^{\circ} \mathrm{C}$ & 1750 & 1700 & $800-2045$ & $1027-727$ \\
\hline Коэффициент теплового расширения, $1 \cdot 10^{-6} /{ }^{\circ} \mathrm{C}$ & $7-8,4$ & 8,2 & $7,4-9$ & $4,3-9$ \\
\hline Удельная теплоемкость, Дж/(кг·K) & 880 & 880 & $750-1020$ & $740-820$ \\
\hline Диэлектрическая проницаемость & 9,8 & 9 & $6,1-7,5$ & $8,3-9,3$ \\
\hline Объемное удельное сопротивление, Ом·см & $>1 \cdot 10^{14}$ & $>1 \cdot 10^{14}$ & $>1 \cdot 10^{16}$ & $>1 \cdot 10^{14}$ \\
\hline
\end{tabular}

Таблица 2. Типы и характеристики подложек из керамических материалов

\begin{tabular}{|c|c|c|c|c|c|c|}
\hline $\begin{array}{l}\text { Материал } \\
\text { подложки }\end{array}$ & $\begin{array}{r}\text { Чистота, } \\
\%\end{array}$ & $\begin{array}{r}\text { Шероховатость } \\
\text { поверхности А, } \\
\text { мкм }\end{array}$ & $\begin{array}{r}\text { Шероховатость } \\
\text { поверхности В, } \\
\text { мкм }\end{array}$ & $\begin{array}{r}\text { Тепло- } \\
\text { провод- } \\
\text { ность, } \\
\mathrm{Bт} / \mathrm{M} \cdot{ }^{\circ} \mathrm{K}\end{array}$ & $\begin{array}{r}\text { Диэлектрическая } \\
\text { проницаемость } \\
\text { (на частоте } \\
1 \text { мгц) }\end{array}$ & $\begin{array}{r}\text { Тангенс угла } \\
\text { диэлектрических } \\
\text { потерь (на частоте } \\
1 \text { мгц) }\end{array}$ \\
\hline Оксид алюминия & 99,6 & 3 & 3 & 26,9 & $9,9 \pm 0,1$ & 0,0001 \\
\hline $\begin{array}{l}\text { Полированный } \\
\text { оксид алюминия }\end{array}$ & 99,6 & 1 & $1 / 12$ & 26,9 & $9,9 \pm 0,1$ & 0,0001 \\
\hline Нитрид алюминия & 98 & 3 & 3 & 170 & 8,6 & 0,001 \\
\hline Оксид бериллия & 99,5 & 3 & 10 & 270 & 6,5 & 0,0004 \\
\hline
\end{tabular}

Высокое качество нанесения металлизации (толщина и стабильность) достигается благодаря использованию высококачественных материалов (паст), строгомуконтролюпараметров материалов и трафаретов и применению высокоточных установок трафаретной печати. Процесс вжигания металлизационных паст выполняется в колпаковых печах в контролируемой азотно-водородной среде при температуре в диапазоне $1300-1700^{\circ} \mathrm{C}$ (рис. 4).

В АО «ТЕСТПРИБОР» освоены также процессы химического и электрохимического нанесения покрытия из никеля и золота:

- электрохимическое никелирование - толщина покрытия до 30 мкм;

- электрохимическое никелирование сплавом никель-фосфортолщина покрытия до 30 мкм;

- химическое никелирование никель-фосфор и никель-бор-толщина покрытия до 10 мкм;

- химическое золочение - толщина покрытия до 2,5 мкм.

Если надетали большоеколичество изолированных поверхностей (например, на печатныхплатах) или изделие

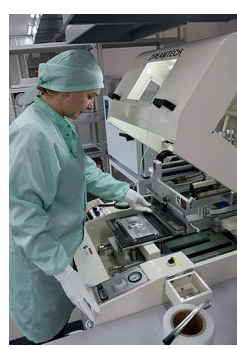
подложки сложной формы, предпочтительно использовать химический способ нанесения покрытия. Такая технология позволяет значительно повысить качество покрытия.

Для формирования подслоя под золотое покрытие, а также в других технологических целях, в частности при металлизации тугоплавкими материалами (молибденом, вольфрамом), на керамических подложках применяются покрытия сплавами никель-бор и никель-фосфор. Толщина покрытия, как правило, не превышает 10 мкм.

При необходимости на никелевое покрытие наносится слой золота химическим или иммерсионным способами, при этом можно гарантировать толщину покрытия
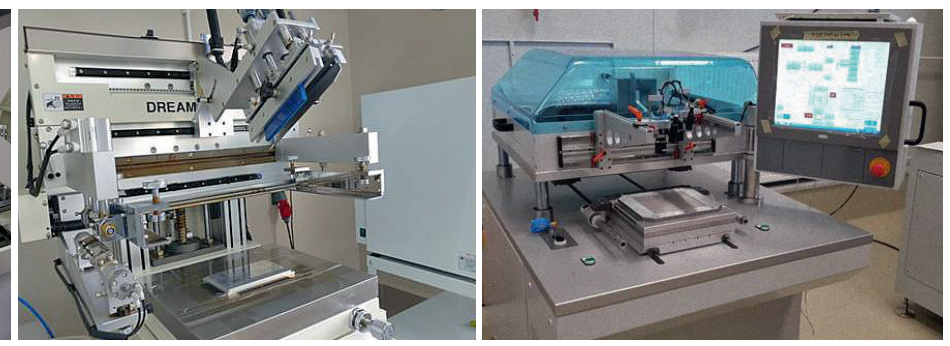

Рис. 3. Оборудование для нанесения металлизации на керамические 

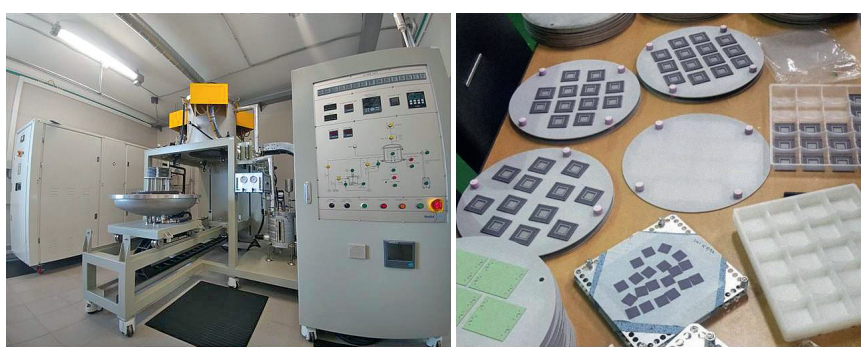

Рис. 4. Вжигание металлизационных паст в колпаковой печи

до 2,5-3 мкм (рис. 5). Как показали испытания, такое покрытие сохраняет паяемость и антикоррозионные свойства.
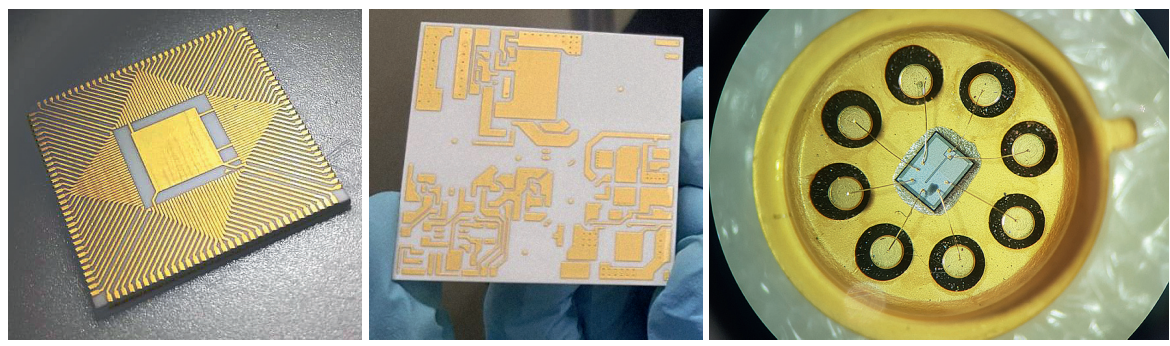

Рис. 5. Образцы продукции с покрытием никель-золото
Высокое качество печатных плат производства AO «ТЕСТПРИБОР» достигается благодаря применению высококачественных трафаретов для печати, изготовленных из материалов с заданными характеристиками. Кроме того, в процессе производства обеспечивается строгий контроль физических параметров паст для печати, оптимально подбираются их состав, режимы нанесения и вжигания металлизации. Особое внимание уделяется проектированию оборудования и оснастки, обеспечивающих повторяемость изделий в партии по толщине и характеристикам металлизации и покрытия, а также равномерность гальванического и химического покрытия, насколько позволяют геометрические параметры изделия.

При производстве керамических изделий В AO «ТЕСТПРИБОР» применяют уникальные современные составы, что позволяет наносить как традиционные, так и редко используемые покрытия, например золотое толщиной более 2 мкм, выполненное химическим способом. Высокие характеристики достигаются также благодаря тщательному контролю качества всех выпускаемых изделий, который осуществляется в несколько этапов по многим параметрам.

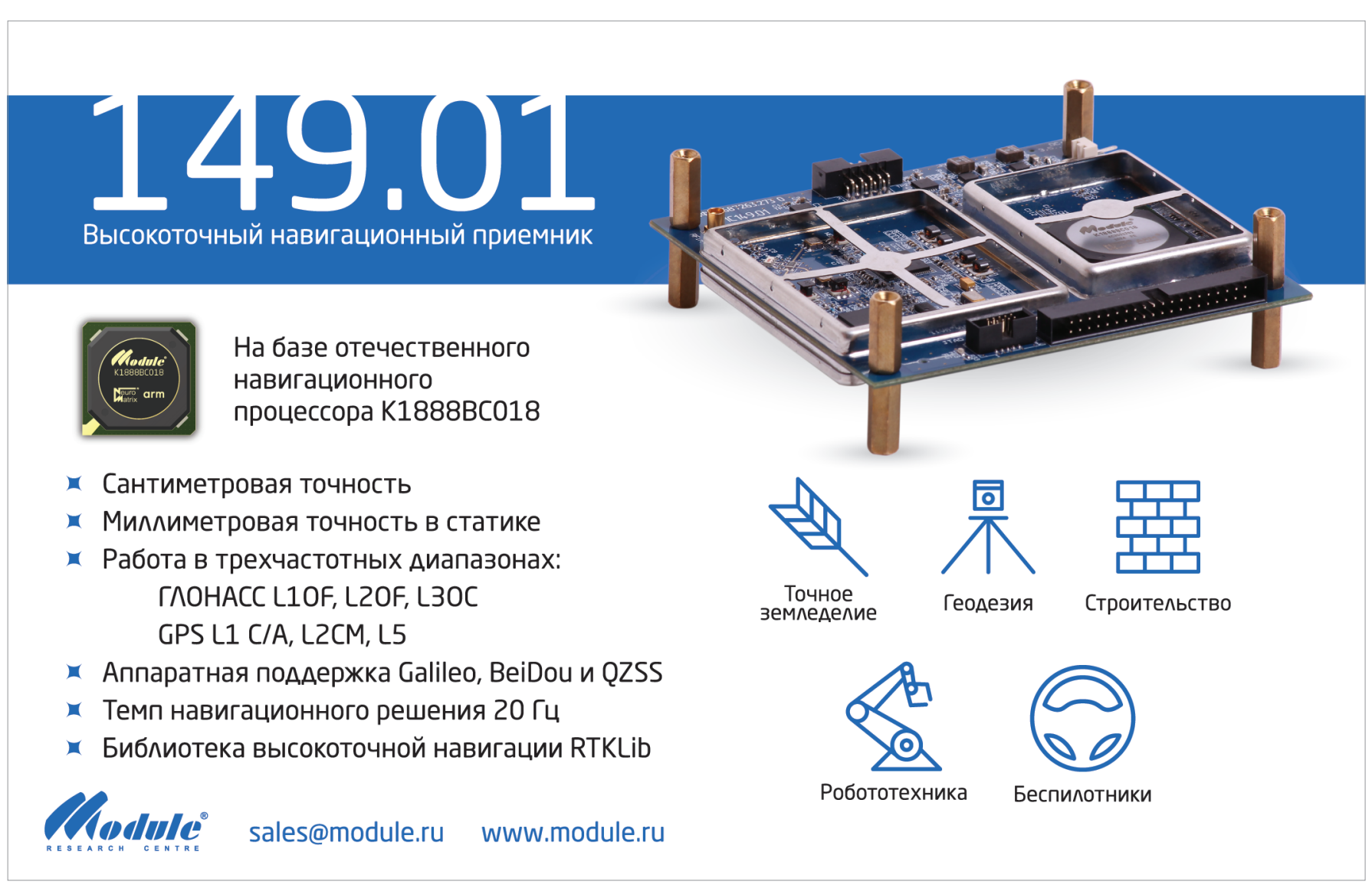




\section{ИЗГОТОВ^ЕНИЕ КЕРАМИЧЕСКИХ ПИАТ И ПОАМОЖKЕК}

\section{ИСПОАЬЗУЕМЫЕ MATEРИАМЫ}

Al203 $96 \%$ Al203 99,6\% AIN

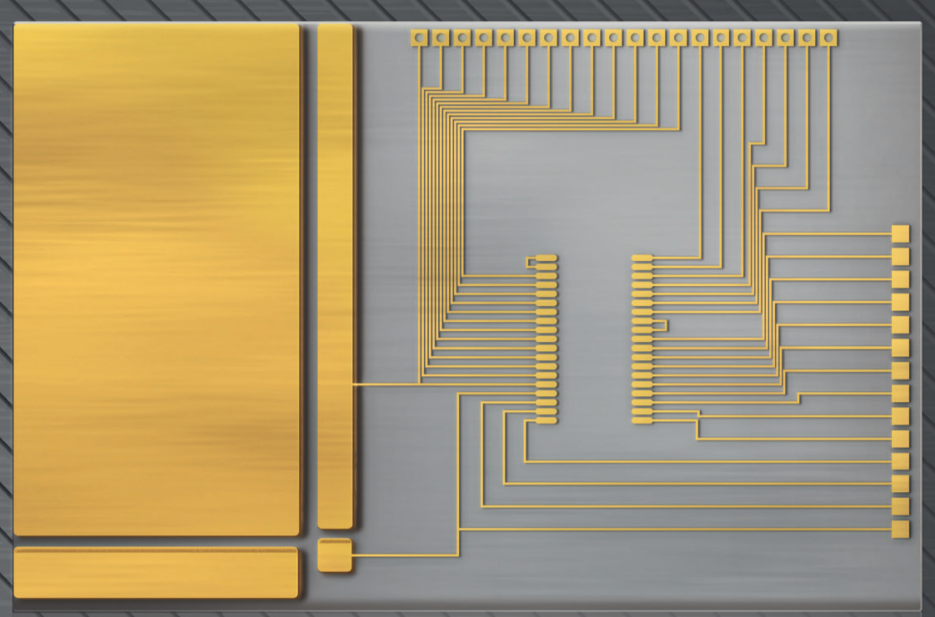

ТОПОЛОГИЧЕСКИЕ НОРМЫ СИГНАЛЬНЫХ САОЕВ

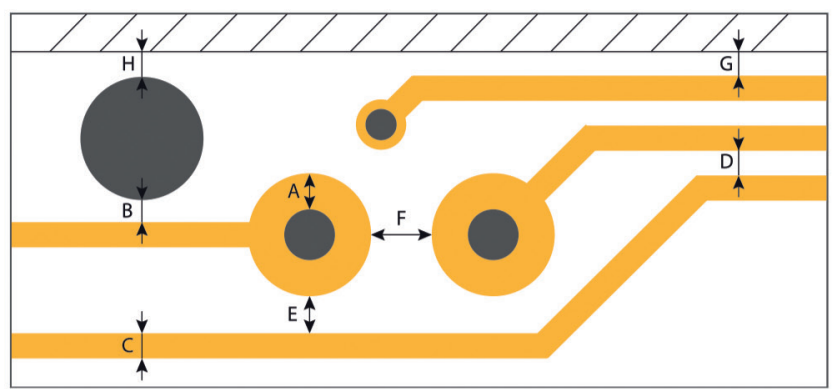

ТОПОЛОГИЧЕСКИЕ НОРМЫ СИ^ОвыХ САОЕв

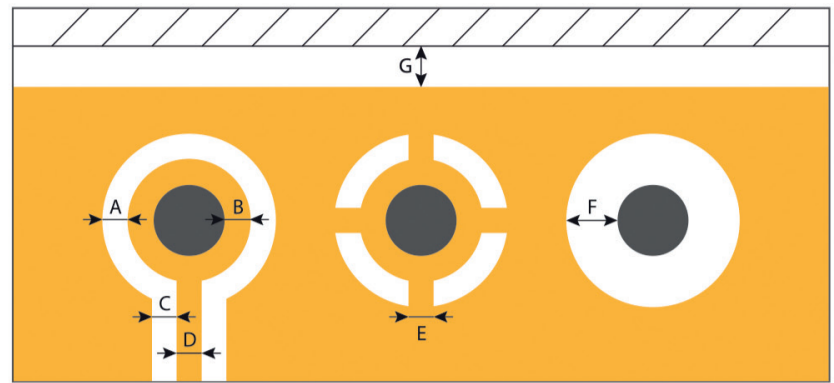

\begin{tabular}{|c|c|c|}
\hline Наименование параметра & $\begin{array}{c}\text { Керамические подложки } \\
\text { с металлизацией на основе } \\
\text { толстопленочной технологии }\end{array}$ & $\begin{array}{c}\text { Керамические подложки } \\
\text { с металлизацией на основе } \\
\text { тонкопленочной технологии }\end{array}$ \\
\hline $\begin{array}{l}\text { Материал проводников } \\
\text { и металлизации }\end{array}$ & $\begin{array}{c}\text { W/Ni-Au или Mo/Ni-Au } \\
\text { (Ni } 5 \text { мкм max, Au 0,5 мкм max) }\end{array}$ & $\begin{array}{l}\text { TiW/Au; TaN/TiW/Au; TiW/Ni/Au; } \\
\text { TaN/TiW/Ni/Au; TaN/NiW/Au/Cu/Ni/Au }\end{array}$ \\
\hline $\begin{array}{c}\text { Поверхностное сопротивление } \\
\text { проводников }\end{array}$ & $10,0 \mathrm{mOM} / \square$ & - \\
\hline $\begin{array}{c}\text { Сопротивление переходных } \\
\text { отверстий размером }(\varnothing 0,2 \times 0,25) \text { мм }\end{array}$ & $6,0 \mathrm{mOM}$ & - \\
\hline A & 0,20 & $0,20 / 020$ \\
\hline B & 0,60 & $0,25 / 025$ \\
\hline C & 0,20 & $0,15 / 0,20$ \\
\hline D & $0,20 / 0,25$ & $0,15 / 0,20$ \\
\hline E & $0,20 / 0,30$ & $0,15 / 0,38$ \\
\hline $\mathrm{F}$ & $0,25 / 0,65$ & $0,15 / 0,30$ \\
\hline G & $0,60 / 0,60$ & $0,25 / 0,50$ \\
\hline $\mathrm{H}$ & $0,60 /-$ & $0,15 /-$ \\
\hline
\end{tabular}

